\title{
The verification of the estimation of transport and sorption parameters in the MATLAB environment. A column test
}

\author{
Monika Okońska ${ }^{1}$, Mariusz Kaczmarek ${ }^{2}$, Piotr Małoszewski $^{3}$, Marek Marciniak $^{1}$ \\ ${ }^{1}$ Adam Mickiewicz University in Poznań, Institute of Physical Geography and Environmental Planning; \\ ul.B. Krygowskiego 10,61-680Poznań, Poland; e-mail: okonska@amu.edu.pl (correspondingauthor), mmarc@amu.edu.pl \\ ${ }^{2}$ Kazimierz Wielki University in Bydgoszcz, Institute of Mechanical Engineering of the Environment and Applied Information \\ Technology; ul. Kopernika 1,85-074 Bydgoszcz, Poland; e-mail: mkk@ukw.edu.pl \\ ${ }^{3}$ AGH University of Science and Technology, Department of Hydrogeology and Engineering Geology; \\ al. A. Mickiewicza 30, 31-871 Krakow, Poland
}

(c) 2017 Authors. This is an open access publication, which can be used, distributed and reproduced in any medium according to the Creative Commons CC-BY 4.0 License requiring that the original work has been properly cited.

Received: 30 January 2017; accepted: 20 December 2017

\begin{abstract}
Mathematical modelling of the migration of pollutants in the groundwater environment requires knowledge of the values of transport and sorption parameters.

The aim of this study was 1) to determine the values of advection, dispersion and sorption parameters of selected tracers that are transported through a porous medium, and 2) to verify the applied parameters estimation procedure.

The authors examined the migration of a solution containing conservative and reactive tracers (chloride, nitrate, lithium and ammonium ions) through a sample of medium sand. The soil sample for the column test was taken from an aquifer near the Tursko groundwater intake (Wielkopolska province, Poland).

The parameter estimation procedure, conducted in the MATLAB environment, included the numerical solution of the differential equations of transport and sorption, and the application of the numerical optimization method. During the identification, the authors tested twelve mathematical models including the advection-dispersion model, as well as single and hybrid (i.e. two-site) sorption models. The authors made a comparison of parameter values obtained by means of the global and local optimization method. The fitting quality was assessed by calculating the root mean square error RMSE and correlation coefficient $r$. As a result of the research, the authors determined the values of the advection-dispersion parameters: hydraulic conductivity $k$, effective porosity $n_{e}$, and longitudinal dispersivity $a$. The authors found out that the nature of lithium ions migration is best captured by the single sorption model (equilibrium sorption), whereas the nature of ammonium ions migration is by the hybrid model with irreversible sorption. Lithium ions on the tested soil revealed low sorption intensity, ammonium ions showed medium intensity, while nitrate ions were transported at the same rate as chloride ions, exhibiting no retardation.

The verification of parameter estimation in the MATLAB environment was carried out by comparing it against the alternative, well-known and often tested method, based on analytical solutions of the transport and sorption equation, combined with optimization within the FIELD and KLUTE-STEP programmes.
\end{abstract}

Keywords: column test, sorption models, parameters, numerical solution, optimization, MATLAB

\section{INTRODUCTION}

Mathematical modelling of substance migration processes in aquifers requires knowledge of the transport parameter values (i.e. the advectiondispersion parameters) and sorption parameters. Determining the value of these parameters is possible through solving the inverse problem, which 
consists in finding the best fitting of the theoretical to the experimental breakthrough curve. Experimental breakthrough curves are recorded during tracer experiments e.g. column tests. Theoretical breakthrough curves are calculated using computer programmes, on the basis of the adopted mathematical model that describes the transport of the tracer through the porous medium. The mathematical model coefficients, i.e. parameter values, are determined during the course of the identification procedure by means of optimization methods.

Optimization methods are broadly and increasingly used in various scientific disciplines (Nocedal \& Wright 2006). The optimization method for assessing the value of the dissolved substance transport parameters is used, among other, in the CXTFIT code (Parker \& Van Genuchten 1984, Toride et al. 1995). Information on the optimization in the MATLAB environment can be found in the works of, e.g., Venkataraman (2009), Marciniak et al. (2009) and Okońska et al. (2016).

The aim of this study was to determine, during the course of the identification procedure in the MATLAB environment, the values of advection, dispersion and sorption parameters of the selected tracers that were transported through the porous medium, and to verify the applied parameters estimation procedure.

During the first stage of the procedure, numerical differential equations of transport and sorption are solved. The second stage involves numerical optimization. Thanks to the numerical solution, it is possible to identify parameter values of various mathematical models, both the parameters of one-dimensional transport and sorption parameters of single and hybrid models. Single sorption models included equilibrium or non-equilibrium sorption, while hybrid sorption models combined equilibrium and non-equilibrium sorption. The estimation of parameters in the MATLAB environment is not limited to mathematical models that have analytical solutions.

The authors tested twelve mathematical models, including the advection-dispersion model for one-dimensional transport, and a wide range of sorption models, including equilibrium sorption models and models combining equilibrium and non-equilibrium sorption. While estimating the parameters, the authors made a comparison of results obtained through global and local optimization. As many as one to four model parameters were identified at a time, and the assessment of the fitting of the theoretical and experimental breakthrough curve was carried out on the basis of two indicators: the root mean square error RMSE and correlation coefficient $r$. A functional interface developed within the programming code makes it easier for the user to conduct identification research in the MATLAB environment.

The verification of parameter estimation was carried out by comparing the values of transport parameters and the values of sorption parameters calculated in the MATLAB environment with the values determined with a well-known alternative analytical-numerical method. The results obtained provide a positive verification of the applied procedure.

The identified values of sorption parameters allow recognising the migration mechanism of particular tracers in the tested type of soil, and in some specific conditions they can be used as initial/input parameters or, after "upscaling", to build numerical models in the local field scale (Gomez-Hernandez et al 2006, Deng et al 2013).

\section{MATERIAL AND METHODS}

\section{Column test}

Tracers breakthrough curves, which served to identify the values of transport and sorption parameters, were recorded during a column test under laboratory conditions. The material used in the test - a sample of medium sand Je-P3/1 was taken from an aquifer in the recharge area of groundwater intake Tursko, in the village of Jedlec, southern Wielkopolska province, Poland (localization of the area is shown in Dragon et al 2016). The sand belongs to uniform grained soil, with a graining non-uniformity coefficient $U=2.12$. The content of organic matter in the soil determined by the calcination loss method amounts to $0.23 \%$, and the content of organic carbon (total organic carbon TOC) determined by the elemental analysis method is $0.021 \%$. The sand contains trace amounts of clay fraction. The clay minerals in it include smectite, kaolinite, 
and illite. The cation exchange capacity CEC was calculated using an empirical formula (Appelo \& Postma 1999) and is equal to $0.81 \mathrm{meq} / 100 \mathrm{~g}$. The sand sample was placed in a filtration column that was $50 \mathrm{~cm}$ long and $9 \mathrm{~cm}$ in diameter (Katalog parametrów hydrogeologicznych 2016). During the column test, the authors examined the migration of the solution containing a conservative tracer (capable of being subject only to advection-dispersion transport) - chloride ions $(\mathrm{Cl})$ and reactive tracers (non-conservative, which may be subject to advection-dispersion transport and sorption) - nitrate ions $\left(\mathrm{NO}_{3}\right)$, lithium ions ( $\mathrm{Li})$ and ammonium ions $\left(\mathrm{NH}_{4}\right)$. The solution containing tracers was injected as a pulse tracer injection of known concentration (Okońska 2006).

The transport of other reactive tracers - zinc and copper ions - was also examined during the column test. Owing to the aim of this paper and due to length limitations, the results obtained for these tracers are not presented - only three reactive tracers characterized by a different intensity of sorption are discussed. Furthermore, groundwater near the Tursko well-field is contaminated with nitrate and ammonium (Dragon et al. 2016).

The concentration of chloride ions, nitrate ions and ammonium ions in the water sample was determined using the ion chromatography (IC) method. The limit of quantification of ions concentration was, respectively, $0.011,0.002$ and $0.001 \mathrm{mg} \cdot \mathrm{dm}^{-3}$. The concentration of lithium ions was determined by means of Flame Atomic Absorption Spectrometry (FAAS). The limit of quantification for those ions was $0.001 \mathrm{mg} \cdot \mathrm{dm}^{-3}$. The recorded breakthrough curves of conservative and reactive tracers are shown in Figure 1.

\section{$C / M_{\text {in }}\left[\mathrm{dm}^{-3}\right]$}

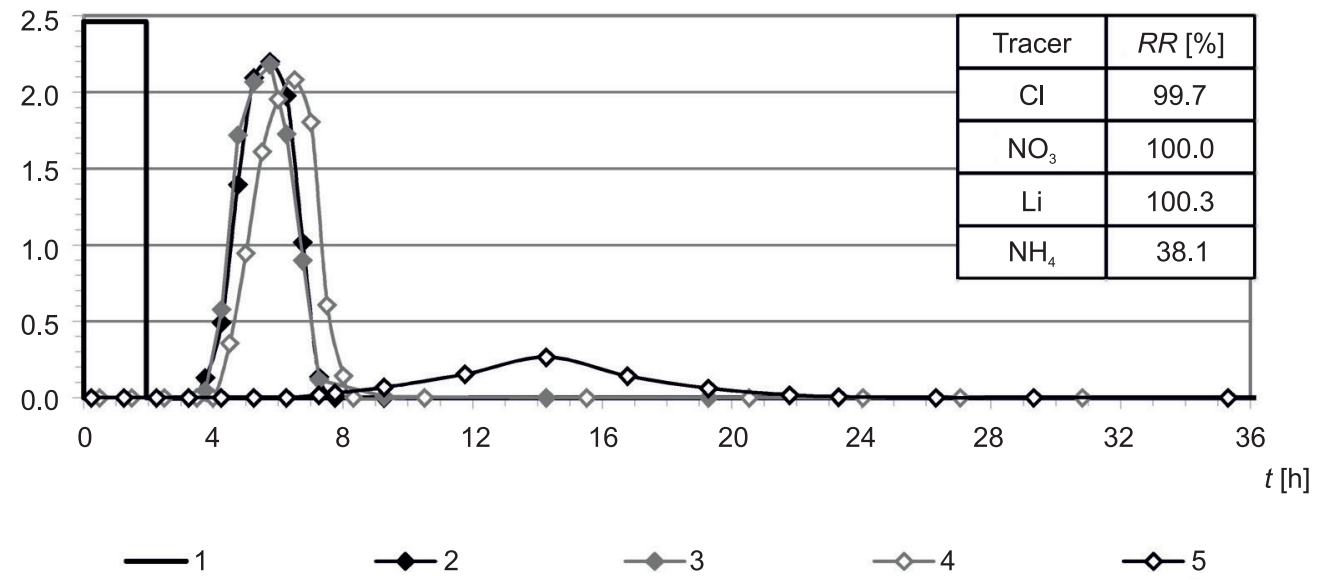

Fig. 1. Experimental tracers breakthrough curves: $C / M_{\text {in }}$ - tracer concentration in relation to the injected tracer mass; 1 - injection, 2 - Cl chloride ions, $3-\mathrm{NO}_{3}$ nitrate ions, 4 - Li lithium ions, $5-\mathrm{NH}_{4}$ ammonium ions; the table shows a percentage of the injected tracer mass retrieved in the column test

During the tests, the authors determined total porosity $n$ by means of the gravimetric method and effective porosity $n_{e}$ by means of the volumetric method (Fetter 2001, Leibundgut et al 2009). The authors also recorded the volumetric flow rate $Q$ through a soil sample, which allowed determining the hydraulic conductivity $k$. Mass balance $R R$ [\%] of each of the tracers was calculated by comparing injected mass of tracer $M_{i n}[\mathrm{M}]$ and recovered mass of tracer in the form of breakthrough curve $M_{\text {out }}[\mathrm{M}]$ :

$$
R R=\frac{M_{\text {out }}}{M_{\text {in }}} \cdot 100
$$

The calculated recovery of ammonium and nitrate ions mass and the lack of nitrite ions prove the lack of ammonium ions transformation into any other forms of nitrogenous compounds. 


\section{Mathematical models}

In the mathematical models, describing the transport of tracers through the sand sample, the authors omitted chemical and bio-chemical reactions, biodegradation, chemo- and electro-osmotic and capillary effects. It was also assumed that the porous material is undeformable and fully saturated with liquid solution and all the material and geometrical parameters present in the model are constant.

The advection-dispersion model (A-D model) was used to describe the transport of the conservative tracer. The authors considered one-dimensional transport, described with the following equation (Weber et al. 1991):

$$
\frac{\partial C}{\partial t}=-\frac{k i}{n_{e}} \frac{\partial C}{\partial x}+\left(D_{M}+\alpha \frac{k i}{n_{e}}\right) \frac{\partial^{2} C}{\partial x^{2}}
$$

where $C$ is the tracer concentration in the liquid phase $\left[\mathrm{M} \cdot \mathrm{L}^{-3}\right], i$ is the hydraulic gradient $\left[\mathrm{L} \cdot \mathrm{L}^{-1}\right]$, $k$ is the hydraulic conductivity $\left[\mathrm{L}^{-\mathrm{T}^{-1}}\right], n_{e}$ is the effective porosity [-], $D_{M}$ is the diffusion coefficient $\left[\mathrm{L}^{2} \cdot \mathrm{T}^{-1}\right], \alpha$ is the longitudinal dispersivity $[\mathrm{L}], t$ is time [T], and $x$ is the distance [L].

This model was also used to characterize the transport of nitrate ions, which are classified as reactive ions (Witczak et al. 2013) and were transported at the same rate as chlorides during the column test (Fig. 1).

Sorption models concerned the transport of reactive (non-conservative) tracers. Single sorption models, taking account of equilibrium or non-equilibrium sorption, were described with the following equation (Weber et al. 1991):

$$
\begin{aligned}
& \frac{\partial C}{\partial t}=-\frac{k i}{n_{e}} \frac{\partial C}{\partial x}+ \\
& +\left(D_{M}+\alpha \frac{k i}{n_{e}}\right) \frac{\partial^{2} C}{\partial x^{2}}-(1-n) \frac{\rho_{s}}{n_{e}} \frac{\partial s}{\partial t}
\end{aligned}
$$

where $n$ is total porosity [-], $\rho_{s}$ is the density of the porous medium $\left[\mathrm{M} \cdot \mathrm{L}^{-3}\right]$ and variable $s$ was substituted with an equation describing one of the following sorption models: the Henry model ( $\mathrm{H}$ model), the Freundlich model ( $\mathrm{F}$ model), the Langmuir model (L model), the irreversible kinetic sorption model (I model), or the reversible kinetic sorption model (R model).
Hybrid models, combining equilibrium $\left(s_{e}\right)$ and non-equilibrium sorption $\left(s_{n}\right)$, were described with a system of equations (Cameron \& Klute 1977):

$$
\left\{\begin{array}{l}
\frac{\partial C}{\partial t}=-\frac{k i}{n_{e}} \frac{\partial C}{\partial x}+ \\
+\left(D_{M}+\alpha \frac{k i}{n_{e}}\right) \frac{\partial^{2} C}{\partial x^{2}}-(1-n) \frac{\rho_{s}}{n_{e}} \frac{\partial s}{\partial t} \\
s=s_{e}+s_{n}
\end{array}\right.
$$

where variables $s_{e}$ and $s_{n}$ were substituted, respectively, with equations describing:

- the Henry model with irreversible sorption (H-I model):

$$
\left\{\begin{array}{l}
s_{e}=K_{d} C \\
\frac{\partial s_{n}}{\partial t}=k_{1} C
\end{array}\right.
$$

- the Henry model with reversible sorption (H-R model):

$$
\left\{\begin{array}{l}
s_{e}=K_{d} C \\
\frac{\partial s_{n}}{\partial t}=k_{2} C-k_{3} s_{n}
\end{array}\right.
$$

- the Freundlich model with irreversible sorption (F-I model):

$$
\left\{\begin{array}{l}
s_{e}=K_{F} C^{n_{F}} \\
\frac{\partial s_{n}}{\partial t}=k_{1} C
\end{array}\right.
$$

- the Freundlich model with reversible sorption (F-R model):

$$
\left\{\begin{array}{l}
s_{e}=K_{F} C^{n_{F}} \\
\frac{\partial s_{n}}{\partial t}=k_{2} C-k_{3} s_{n}
\end{array}\right.
$$

- the Langmuir model with irreversible sorption (L-I model):

$$
\left\{\begin{array}{l}
s_{e}=\frac{\alpha_{L} \beta_{L} C}{1+\alpha_{L} C} \\
\frac{\partial s_{n}}{\partial t}=k_{1} C
\end{array}\right.
$$


- the Langmuir model with irreversible sorption (L-R model):

$$
\left\{\begin{array}{l}
s_{e}=\frac{\alpha_{L} \beta_{L} C}{1+\alpha_{L} C} \\
\frac{\partial s_{n}}{\partial t}=k_{2} C-k_{3} s_{n}
\end{array}\right.
$$

where $K_{d}$ is the Henry distribution coefficient $\left[\mathrm{L}^{3} \cdot \mathrm{M}^{-1}\right], k_{1}$ is the irreversible sorption rate coefficient $\left[\mathrm{L}^{3} \cdot \mathrm{M}^{-1} \cdot \mathrm{T}^{-1}\right], k_{2}$ is the first reversible sorption rate coefficient $\left[\mathrm{L}^{3} \cdot \mathrm{M}^{-1} \cdot \mathrm{T}^{-1}\right], k_{3}$ is the second reversible sorption rate coefficient $\left[\mathrm{T}^{-1}\right], K_{F}$ is the Freundlich sorption coefficient $\left[\mathrm{L}^{3} \cdot \mathrm{M}^{-1}\right]$, $n_{F}$ is the Freundlich sorption exponent [-], $\alpha_{L}$ is the Langmuir constant $\left[\mathrm{L}^{3} \cdot \mathrm{M}^{-1}\right]$, and $\beta_{L}$ is the total sorption capacity of the solid phase $\left[\mathrm{M} \cdot \mathrm{M}^{-1}\right]$.

\section{Parameter estimation}

The parameters estimation procedure, carried out in the MATLAB environment, involved the numerical solution of transport and sorption differential equations, and the application of numerical optimization.

The equations were solved in the MATLAB environment with the pdepe solver, which uses the numerical finite element method (FEM). When solving equations describing the migration by pulse-type injection, the authors assumed appropriate boundary conditions. The authors assumed the initial condition, determining the distribution of concentrations in all of the analysed area at time $t=0$, as:

$C(x, t=0)=0$ where $x \geq 0$

At column input, the authors assumed firsttype boundary condition (i.e. the Dirichlet condition) in the following way:

$C(x=0, t)=C_{\text {in }}$ where $0<t \leq t_{\text {in }}$

where $t_{\text {in }}$ - the time interval of the tracer injection, when $C(t)=C_{i n}$ at the input [T].

At column output, the authors assumed second-type boundary condition (i.e. the Neumann condition):

$$
\left.\frac{\partial C(x, t)}{\partial x}\right|_{x=L}=0 \text { where } t \geq 0
$$

where $L$ - the column length [L].

The identification procedure scheme using numerical optimization in the MATLAB environment is shown in Figure 2.

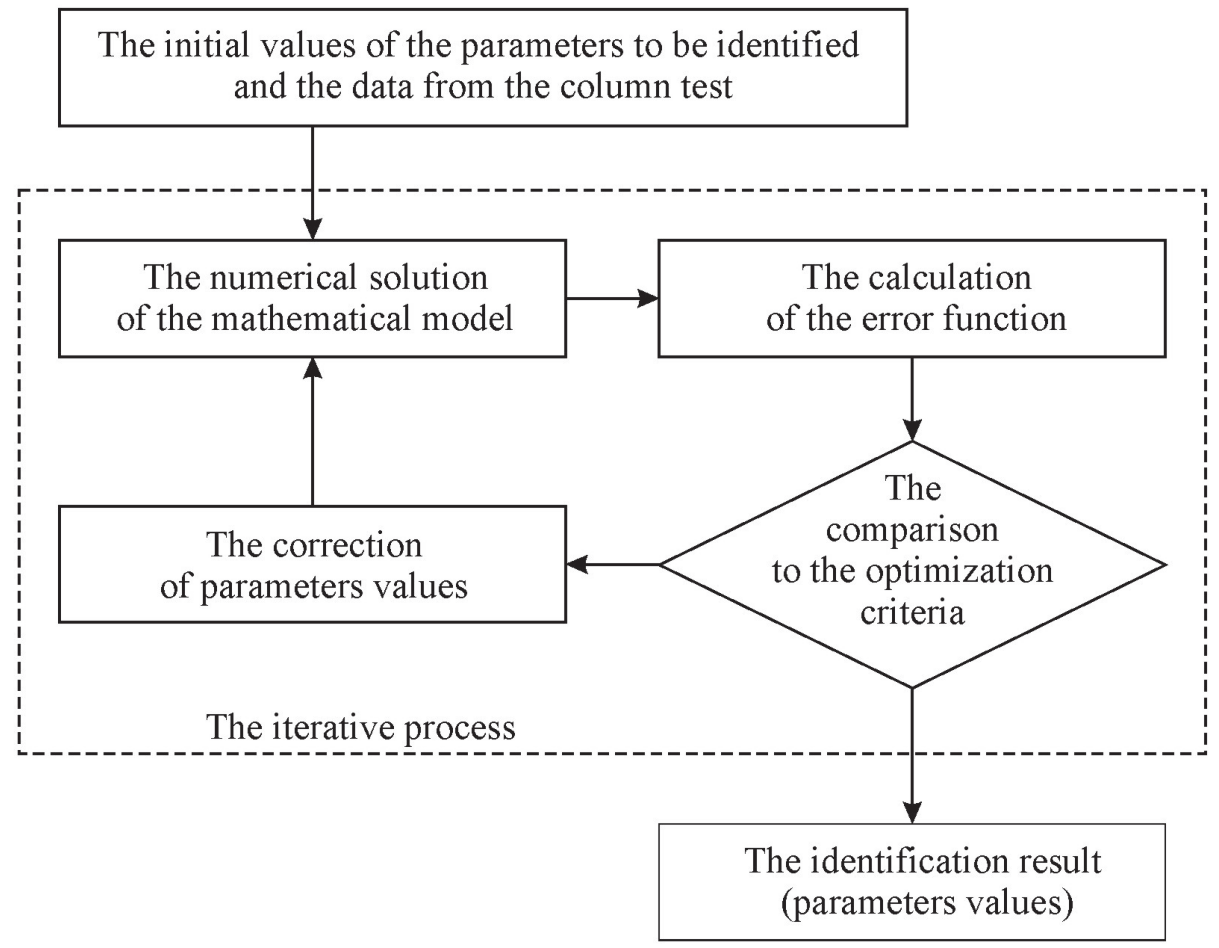

Fig. 2. The identification procedure scheme using numerical optimization 
The authors introduced the following initial values of the identified parameters and data from the column test into the model: the soil sample height, the value of the hydraulic gradient, the value of the effective porosity, data on the experimental points and injection. As the density of laboratory measurements was lower than the required number of steps of integrating differential equations, the time intervals between the measurements were supplemented with additional points using linear interpolation.

In the advection-dispersion model, the following parameters were searched for: the value of hydraulic conductivity $k$, and the value of longitudinal dispersivity $\alpha$. In the sorption models, the authors identified sorption parameters. The value of hydraulic conductivity $k$ and the value of longitudinal dispersivity $\alpha$ were substituted with parameters values determined for chloride ions in the advection-dispersion model. The values of transport parameters, determined on the basis of the chloride ions breakthrough curve, were confirmed by the optimization of nitrate ions breakthrough curves.

The calculations were made using both the global and local optimization procedures. Spotting the point where the error function assumes a value lower than in the neighbouring points means finding a local minimum. A local minimum can be a global minimum at the same time. The global minimum is a point at which the error function assumes the lowest value within the whole search range (Nocedal \& Wright 2006).

For identification calculations the authors used the Optimization Toolbox bundle and the in-built lsqcurvefit function for the non-linear solution of the optimization problem. This function, using the extra option large scale optimization applies the area-restricted search method (Coleman \& Li 1994).

In order to identify the transport and sorption parameters using global optimization methods in the MATLAB environment, the authors used the patternsearch function which allows searching for the error function minimum by means of the pattern search method. This method requires providing the initial point and allows applying optimization concerning equivalent nodes (linear and non-linear) and non-equivalent nodes for the parameters searched for.
Searching for the error function minimum involved from a dozen or so to several hundred iteration steps, and went on until the set optimization criteria (the defined arguments of the optimset function) were met. As for the local optimization, it was assumed that the optimization procedure would be stopped when the size of the current step of the independent variable was smaller than the set value $\operatorname{Tol} X=1 \mathrm{e}-12$. The authors also defined the criterion of function value TolFun in the form of the first-order optimality measure. This criterion ought to assume a value of zero in the local minimum. The authors assumed that TolFun $=1 \mathrm{e}-15$. As for the global optimization, it was assumed that the optimization procedure would be stopped when the scale of mesh size changes was smaller than the set value TolMesh, which was 1e-12.

The quality estimation of the fitting of the theoretical tracer breakthrough curve to the experimental breakthrough curve, recorded during the column test, was checked using the root mean square error RMSE and the correlation coefficient $r$. In order to calculate the RMSE as the sum of the squared differences between the values of measured concentration $C_{m}$ and that obtained from simulation $C_{t}$, only concentrations occurring at measurement times $t_{m}$ were taken into account:

$\operatorname{RMSE}=\sum_{k=1}^{N}\left[C_{m}\left(t_{m}\right)-C_{t}\left(\mathrm{~A}, t_{m}\right)\right]^{2}$

where $A$ - the set of parameters to be identified. Linear correlation coefficient $r$ was calculated with the following formula:

$r=\frac{\operatorname{cov}\left(C_{m}, C_{t}\right)}{\sigma_{C_{m}} \sigma_{C_{t}}}$

where cov is the covariance between the values observed $C_{m}$ and calculated $C_{t}$ at times $t_{m}$, and $\sigma$ is standard deviation.

\section{Verification}

The authors verified the applied parameter estimation procedure in the MATLAB environment by interpreting tracer breakthrough curves in the column test with an alternative calculation method (Hendry et al. 1999, Fohrmann et al. 2001). With this method the authors assumed: 
- the advection-dispersion model for chloride ions and nitrate ions (see Eq. (2)):

$\frac{\partial C}{\partial t}=-v \frac{\partial C}{\partial x}+D \frac{\partial^{2} C}{\partial x^{2}}$ where $D=\alpha \frac{k i}{n_{e}}$

where $C$ is the tracer concentration in water $\left[\mathrm{M} \cdot \mathrm{L}^{-3}\right], t$ is time $[\mathrm{T}], v$ is the average linear pore water velocity $\left[\mathrm{L} \cdot \mathrm{T}^{-1}\right], x$ is the distance along the column $[\mathrm{L}], D$ is the coefficient of hydrodynamic dispersion $\left[\mathrm{L}^{2} \cdot \mathrm{T}^{-1}\right], \alpha$ is dispersivity of the porous medium [L], $k$ is the hydraulic conductivity $\left[\mathrm{L} \cdot \mathrm{T}^{-1}\right], i$ is the hydraulic gradient $\left[\mathrm{L} \cdot \mathrm{L}^{-1}\right]$, and $n_{e}$ is the effective porosity [-];

- the single sorption model taking account of linear equilibrium sorption (instantaneous sorption), i.e. the Henry model, for lithium ions:

$\frac{\partial C}{\partial t} R=-v \frac{\partial C}{\partial x}+D \frac{\partial^{2} C}{\partial x^{2}}$

where $R=1+\frac{\rho_{s}(1-n)}{n_{e}} K_{d}$

where $R$ is retardation $[-], \rho_{s}$ is the density of the porous medium $\left[\mathrm{M} \cdot \mathrm{L}^{-3}\right], n$ is total porosity [-] and $K_{d}$ is the Henry distribution coefficient $\left[\mathrm{L}^{3} \cdot \mathrm{M}^{-1}\right]$;

- the hybrid sorption model (the Henry model with irreversible sorption) for ammonium ions (see Eq. (5)):

$\frac{\partial C}{\partial t} R+\lambda C=-v \frac{\partial C}{\partial x}+D \frac{\partial^{2} C}{\partial x^{2}}$

where $\lambda=\frac{\rho_{s}(1-n)}{n_{e}} k_{1}$

where $\lambda$ is decay constant $\left[\mathrm{T}^{-1}\right]$ and $k_{1}$ is the irreversible sorption rate coefficient $\left[\mathrm{L}^{3} \cdot \mathrm{M}^{-1} \cdot \mathrm{T}^{-1}\right]$.

The mathematical models were solved analytically, and then parameter values were calculated using FIELD and KLUTE-STEP programmes. Those programmes use an optimization method that relies on the least square method (FIELD) and the trialand-error procedure (KLUTE-STEP) (Maloszewski
1981, Maloszewski 1997). The fitting model parameters were, respectively: in Equation [16] transport parameters $v$ and $\alpha$, in Equation (17) sorption parameter $R$, in Equation (18) sorption parameters $R$ and $\lambda$. With those programmes the mass recovery of tracer $R R$ [\%] was calculated (see Eq. (1)):

$$
R R(t)=\frac{Q}{M_{i n}} \int_{0}^{t} C(t) d t \cdot 100
$$

where $Q$ is the volumetric flow rate $\left[\mathrm{L}^{3} \cdot \mathrm{T}^{-1}\right], C$ is the tracer concentration in the liquid phase $\left[\mathrm{M} \cdot \mathrm{L}^{-3}\right], t$ is time [T] and $M_{i n}$ is the injected mass of tracer [M].

The authors also determined the level of fitting the theoretical curve to experimental data in the form of model efficiency indicator $M E$ [\%], where $M E=r \cdot 100$.

A comparison of parameter estimation results obtained in MATLAB with additional simple analytical calculations was also conducted. Longitudinal dispersivity $\alpha$ and retardation $R$ were calculated according to equations presented in Kleczkowski (ed, 1984), Appelo \& Postma (1999) and Małecki et al (2006).

\section{RESULTS}

\section{Advection-dispersion model parameters}

The value of hydraulic conductivity $k$, which was determined during the column test and introduced into the advection-dispersion model as an initial value, did not change following the identification. Following the interpretation of the recorded experimental breakthrough curve of chloride ions, the value of longitudinal dispersivity $\alpha$ of $0.003 \mathrm{~m}$ for transport distance $x=0.47 \mathrm{~m}$ was obtained (see Tab. 1). The calculated values of transport parameters are confirmed by the numerical optimization result received for the nitrate ions breakthrough curve. In both cases, the global and local optimization method gave the same result. The local minimum proved the same as the global minimum.

Table 1

The values of parameters determined for the advection-dispersion model

\begin{tabular}{|c|c|c|c|c|c|c|c|c|c|c|c|}
\hline \multirow{2}{*}{ Model } & \multicolumn{2}{|c|}{ Parameter } & \multicolumn{3}{|c|}{ Chloride ions } & \multicolumn{3}{|c|}{ Nitrate ions } & \multicolumn{3}{|c|}{ Lithium ions } \\
\hline & symbol & unit & value & RMSE & $r$ & value & RMSE & $r$ & value & RMSE & $r$ \\
\hline \multirow{3}{*}{ A-D } & $k$ & $\mathrm{~m} \cdot \mathrm{s}^{-1}$ & $4.17 \mathrm{E}-04$ & \multirow{3}{*}{0.59} & \multirow{3}{*}{0.99} & $4.26 \mathrm{E}-04$ & \multirow{3}{*}{0.11} & \multirow{3}{*}{0.99} & $3.76 \mathrm{E}-04$ & \multirow{3}{*}{0.17} & \multirow{3}{*}{0.97} \\
\hline & $n_{e}$ & - & 0.31 & & & 0.31 & & & 0.31 & & \\
\hline & $\alpha$ & $\mathrm{m}$ & 0.0029 & & & 0.0033 & & & 0.0031 & & \\
\hline
\end{tabular}

Explanation: RMSE - root mean squared error; $r$ - correlation coefficient. 
Furthermore, advection-dispersion model parameters for lithium ions, regarded by some authors as a conservative tracer (Wrenn et al. 1997, Boutilier et al. 2008), were also calculated. However, in this case, a better fitting of the theoretical and experimental breakthrough curve of lithium ions was obtained for the sorption model. Moreover, the position of the experimental breakthrough curve of lithium ions against the chloride ions breakthrough curve implies that those ions ought to be considered as a reactive tracer, although subject to limited sorption (Reimus et al 2003, Fernandez-Garcia et al 2004).

Figure 3 shows theoretical breakthrough curves of lithium ions and nitrate ions, calculated in the MATLAB environment, against experimental points.

$$
C / M_{\text {in }}\left[\mathrm{dm}^{-3}\right]
$$

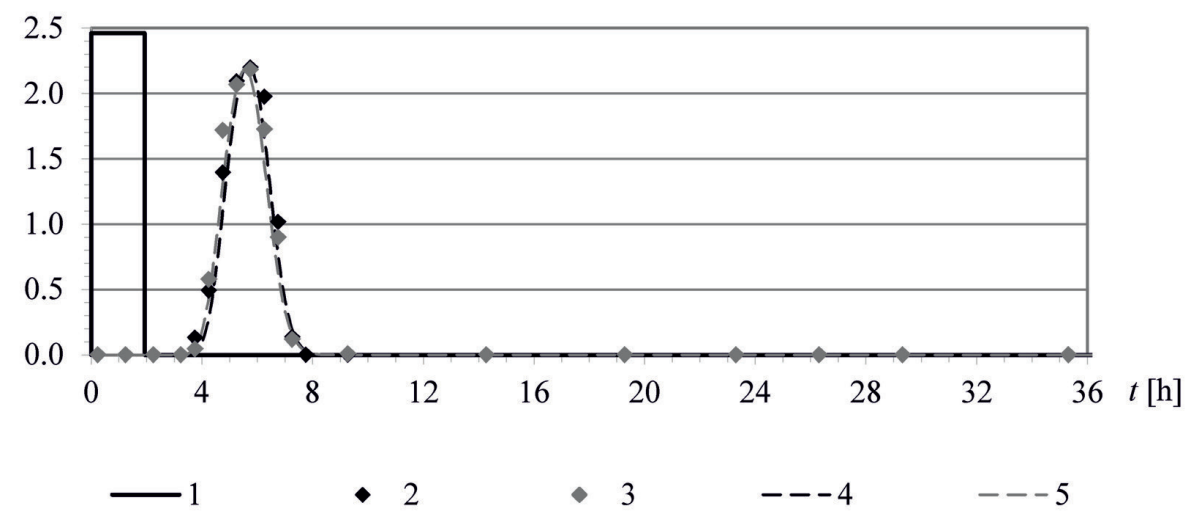

Fig. 3. Theoretical breakthrough curves of chloride ions $(\mathrm{Cl})$ and nitrate ions $\left(\mathrm{NO}_{3}\right)$ calculated in the MATLAB environment, $A-D$ model: $C / M_{i n}$ - tracer concentration in relation to the injected tracer mass; 1 - injection, 2 - Cl experimental data, $3-\mathrm{NO}_{3}$ experimental data, $4-\mathrm{Cl} A-D$ model, $5-\mathrm{NO}_{3} A-D$ model

\section{Sorption model parameters}

The estimation of the sorption parameters of lithium ions and ammonium ions was made for all sorption models described with Equations (3)(10). Table 2 shows parameters values calculated with the local optimization method. In almost all cases, calculations using global optimization gave an identical result.

In the case of lithium ions, the minimal value of RMSE and the highest value of correlation coefficient $r$ were obtained for the Freundlich model (F model) and the Freundlich model with reversible sorption (F-R model). It can be presumed that the single sorption model (F model) describes the transport of this tracer through the porous medium well enough. As for ammonium ions, the lowest value of RMSE and the highest value of correlation coefficient $r$ were obtained for hybrid sorption models: the Freundlich model with irreversible sorption (F-I model) and the Freundlich model with reversible sorption (F-R model).
Considering the result of tracer mass balance (Fig. 1), the nature of ammonium ions transport is better captured by the former model (F-I model).

Figure 4 shows selected theoretical tracer breakthrough curves, calculated during identification using the numerical optimization method in the MATLAB environment.

Due to searching for a solution in the whole specified range of values, the calculations made with the global optimization method are a longer process, particularly in the case of multi-parameter models. Calculations made with the local optimization method, where solutions are searched for near the start-up point, take a shorter time. However, in the case of some tested sorption models, local optimization generated more than one solution (Fig. 5A, B), depending on the values of initial parameters. In such a case, for the given model, the authors chose the result of calculations made with the local optimization method, which is characterised by the lowest value of RMSE and the highest value of the correlation coefficient $r$. 
Table 2

Parameters values determined for single and hybrid sorption models (Okońska et al. 2016)

\begin{tabular}{|c|c|c|c|c|c|c|c|c|}
\hline \multirow{2}{*}{ Model } & \multicolumn{2}{|c|}{ Parameter } & \multicolumn{3}{|c|}{ Lithium ions } & \multicolumn{3}{|c|}{ Ammonium ions } \\
\hline & symbol & unit & value & RMSE & $r$ & value & RMSE & $r$ \\
\hline $\mathrm{H}$ & $K_{d}$ & $\mathrm{dm}^{3} \cdot \mathrm{kg}^{-1}$ & $1.82 \mathrm{E}-02$ & 0.17 & 0.97 & $2.89 \mathrm{E}-01$ & 0.062 & 0.90 \\
\hline \multirow{2}{*}{$\mathrm{F}$} & $K_{F}$ & $\mathrm{dm}^{3} \cdot \mathrm{kg}^{-1}$ & $2.85 \mathrm{E}-03$ & \multirow{2}{*}{0.15} & \multirow{2}{*}{0.99} & $3.22 \mathrm{E}-01$ & \multirow{2}{*}{0.030} & \multirow{2}{*}{0.90} \\
\hline & $n_{F}$ & - & 2.00 & & & 2.00 & & \\
\hline \multirow{2}{*}{$\mathrm{L}$} & $\alpha_{L}$ & $\mathrm{dm}^{3} \cdot \mathrm{mg}^{-1}$ & $2.01 \mathrm{E}-02$ & \multirow{2}{*}{0.17} & \multirow{2}{*}{0.97} & $1.00 \mathrm{E}+00$ & \multirow{2}{*}{0.029} & \multirow{2}{*}{0.88} \\
\hline & $\beta_{L}$ & $\mathrm{mg} \cdot \mathrm{kg}^{-1}$ & $1.00 \mathrm{E}+00$ & & & $8.54 \mathrm{E}-01$ & & \\
\hline I & $k_{1}$ & $\mathrm{dm}^{3} \cdot \mathrm{kg}^{-1} \cdot \mathrm{s}^{-1}$ & $2.22 \mathrm{E}-14$ & 0.27 & 0.85 & $1.12 \mathrm{E}-04$ & 0.027 & -0.19 \\
\hline \multirow{2}{*}{$\mathrm{R}$} & $k_{2}$ & $\mathrm{dm}^{3} \cdot \mathrm{kg}^{-1} \cdot \mathrm{s}^{-1}$ & $1.74 \mathrm{E}-04$ & \multirow{2}{*}{0.17} & \multirow{2}{*}{0.97} & $4.20 \mathrm{E}-05$ & \multirow{2}{*}{0.024} & \multirow{2}{*}{0.36} \\
\hline & $k_{3}$ & $\mathrm{~s}^{-1}$ & $9.63 \mathrm{E}-03$ & & & $4.03 \mathrm{E}-05$ & & \\
\hline \multirow{2}{*}{$\mathrm{H}-\mathrm{I}$} & $K_{d}$ & $\mathrm{dm}^{3} \cdot \mathrm{kg}^{-1}$ & $1.82 \mathrm{E}-02$ & \multirow{2}{*}{0.17} & \multirow{2}{*}{0.97} & $3.11 \mathrm{E}-01$ & \multirow{2}{*}{0.011} & \multirow{2}{*}{0.92} \\
\hline & $k_{1}$ & $\mathrm{dm}^{3} \cdot \mathrm{kg}^{-1} \cdot \mathrm{s}^{-1}$ & $3.08 \mathrm{E}-14$ & & & $1.29 \mathrm{E}-05$ & & \\
\hline \multirow{3}{*}{ F-I } & $K_{F}$ & $\mathrm{dm}^{3} \cdot \mathrm{kg}^{-1}$ & $1.13 \mathrm{E}-02$ & \multirow{3}{*}{0.16} & \multirow{3}{*}{0.98} & $3.14 \mathrm{E}-01$ & \multirow{3}{*}{0.005} & \multirow{3}{*}{0.98} \\
\hline & $n_{F}$ & - & 1.25 & & & 1.47 & & \\
\hline & $k_{1}$ & $\mathrm{dm}^{3} \cdot \mathrm{kg}^{-1} \cdot \mathrm{s}^{-1}$ & $2.34 \mathrm{E}-14$ & & & $9.25 \mathrm{E}-06$ & & \\
\hline \multirow{3}{*}{ L-I } & $\alpha_{L}$ & $\mathrm{dm}^{3} \cdot \mathrm{mg}^{-1}$ & $2.01 \mathrm{E}-02$ & & & $5.39 \mathrm{E}-01$ & & \\
\hline & $\beta_{L}$ & $\mathrm{mg} \cdot \mathrm{kg}^{-1}$ & 1.00 & 0.17 & 0.97 & $9.86 \mathrm{E}-01$ & 0.006 & 0.97 \\
\hline & $k_{1}$ & $\mathrm{dm}^{3} \cdot \mathrm{kg}^{-1} \cdot \mathrm{s}^{-1}$ & $2.23 \mathrm{E}-14$ & & & $9.41 \mathrm{E}-06$ & & \\
\hline & $K_{d}$ & $\mathrm{dm}^{3} \cdot \mathrm{kg}^{-1}$ & $6.42 \mathrm{E}-08$ & & & $3.05 \mathrm{E}-01$ & & \\
\hline $\mathrm{H}-\mathrm{R}$ & $k_{2}$ & $\mathrm{dm}^{3} \cdot \mathrm{kg}^{-1} \cdot \mathrm{s}^{-1}$ & $1.70 \mathrm{E}-04$ & 0.17 & 0.97 & $1.34 \mathrm{E}-05$ & 0.010 & 0.91 \\
\hline & $k_{3}$ & $\mathrm{~s}^{-1}$ & $9.40 \mathrm{E}-03$ & & & $4.52 \mathrm{E}-06$ & & \\
\hline & $K_{F}$ & $\mathrm{dm}^{3} \cdot \mathrm{kg}^{-1}$ & $2.85 \mathrm{E}-03$ & & & $3.11 \mathrm{E}-01$ & & \\
\hline F $\mathrm{P}$ & $n_{F}$ & - & 2.00 & 015 & 000 & 1.47 & 0005 & 098 \\
\hline $\mathrm{F}-\mathrm{R}$ & $k_{2}$ & $\mathrm{dm}^{3} \cdot \mathrm{kg}^{-1} \cdot \mathrm{s}^{-1}$ & $3.06 \mathrm{E}-07$ & 0.15 & 0.99 & $9.77 \mathrm{E}-06$ & 0.005 & 0.98 \\
\hline & $k_{3}$ & $\mathrm{~s}^{-1}$ & $1.00 \mathrm{E}+00$ & & & $2.40 \mathrm{E}-06$ & & \\
\hline & $\alpha_{L}$ & $\mathrm{dm}^{3} \cdot \mathrm{mg}^{-1}$ & $3.16 \mathrm{E}-07$ & & & $5.27 \mathrm{E}-01$ & & \\
\hline$L-R$ & $\beta_{L}$ & $\mathrm{mg} \cdot \mathrm{kg}^{-1}$ & $3.06 \mathrm{E}-01$ & 0.17 & 0.97 & $9.99 \mathrm{E}-01$ & 0006 & 0.97 \\
\hline & $k_{2}$ & $\mathrm{dm}^{3} \cdot \mathrm{kg}^{-1} \cdot \mathrm{s}^{-1}$ & $1.57 \mathrm{E}-04$ & & & $9.45 \mathrm{E}-06$ & & \\
\hline & $k_{3}$ & $\mathrm{~s}^{-1}$ & $8.72 \mathrm{E}-03$ & & & $2.44 \mathrm{E}-14$ & & \\
\hline
\end{tabular}

Explanation: for each tracer, the model with the lowest value of RMSE and the highest value of correlation coefficient $r$ is in bold.

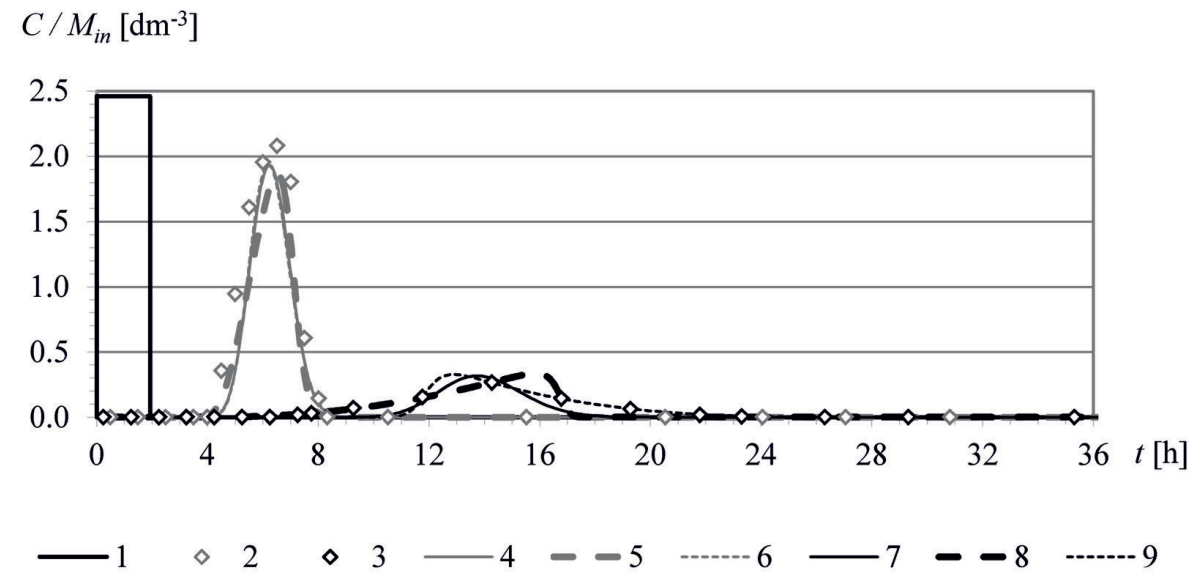

Fig. 4. Selected theoretical breakthrough curves of lithium ions $(\mathrm{Li})$ and ammonium ions $\left(\mathrm{NH}_{4}\right)$ calculated in the MATLAB environment, compared with experimental points: $C / M_{\text {in }}$ - tracer concentration in relation to the injected tracer mass; 1 -injection, 2 - Li experimental data, 3 - $\mathrm{NH}_{4}$ experimental data, 4 - Li H model, 5 - Li F model, 6 - Li L model, 7 - $\mathrm{NH}_{4} \mathrm{H}-\mathrm{I} \mathrm{model,}$ $8-\mathrm{NH}_{4} \mathrm{~F}-\mathrm{I}$ model, $9-\mathrm{NH}_{4} \mathrm{~L}-\mathrm{I}$ model; bold dotted line refers to the solution for the model with the lowest value of RMSE and the highest value of correlation coefficient $r$ 

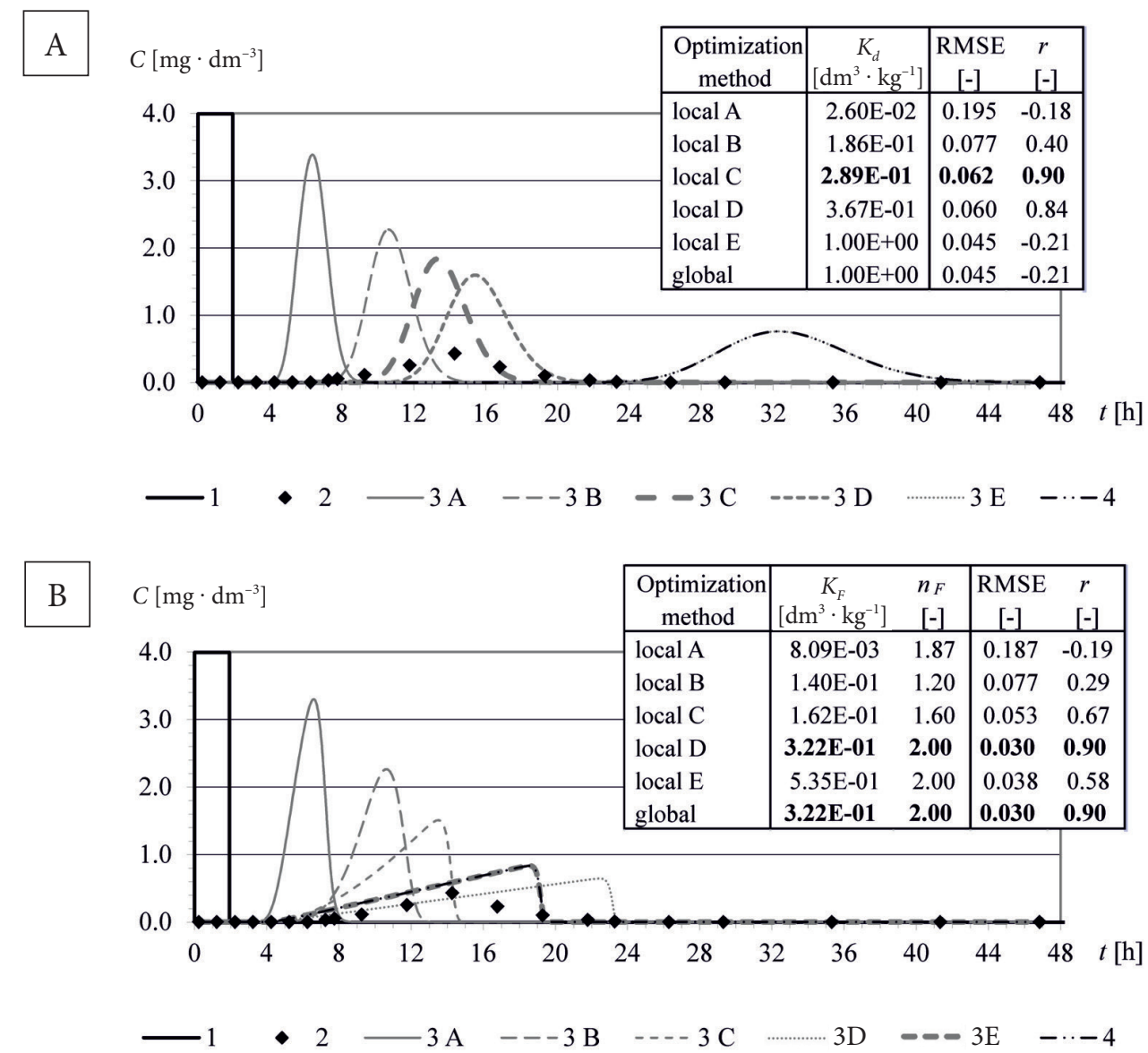

Fig. 5. The results of local and global optimization for the two tested sorption models (A-H model, B-F model), ammonium ions: 1 -injection, 2 - experimental data, $3 A$ - local A, 3B - local B, 3C-local C, 3D-local D, $3 E$-local E, 4 - global; the table shows the identified values of sorption parameters and the calculated RMSE and $r$ indicators of fitting the theoretical breakthrough curves to experimental points

\section{DISCUSSION}

In order to verify the estimation of parameters in the MATLAB environment, the authors compared transport parameters values with the values calculated in the FIELD programme (Tab. 3). Both methods give similar results. The simple analytical calculations of longitudinal dispersivity $\alpha$, which is equal $0.004 \mathrm{~m}$, also confirm the result.

The sorption parameters values identified in the MATLAB environment were also compared with the results of the calculations using the KLUTE-STEP programme (Tab. 4). The comparison was carried out for $\mathrm{H}$ model and $\mathrm{H}-\mathrm{I}$ model as those models were selected in the alternative method as reflecting the nature of migration of, respectively, lithium ions and ammonium ions. The verification proved that the parameters estimation procedure in the MATLAB environment identifies correctly the values of sorption model parameters.
Figure 6 shows the visualisation of fitting the theoretical curves, calculated in FIELD and KLUTE-STEP programmes, to measurement points.

In the parameter estimation procedure in the MATLAB environment, the mathematically best fitting of theoretical curves to experimental points, as for lithium ions, was achieved for the Freundlich model (F model), whereas the alternative method shows that a very good fitting can be achieved for the Henry model (H model). When describing the migration of lithium ions in the analysed case, both the sorption models can be used, as the differences in the results are not big. The Henry model is a peculiar case of the Freundlich model, in which the value of parameter $n_{F}$ is 1.0. Distribution density of experimental points is too small to decide whether the experimental breakthrough curve is indeed symmetrical (H model, Fig. 7A), or slightly skewed (F model, Fig. 7B). 
Table 3

Transport parameters values calculated in the MATLAB environment and the FIELD programme

\begin{tabular}{|c|c|c|c|c|}
\hline \multicolumn{3}{|c|}{ Chloride and nitrate ions } & MATLAB & FIELD \\
\hline \multirow{2}{*}{ model } & parameter & unit & value & value \\
\hline \multirow{3}{*}{ A-D } & $k$ & $\mathrm{~m} \cdot \mathrm{s}^{-1}$ & $4.17 \mathrm{E}-04$ & $4.42 \mathrm{E}-04$ \\
\cline { 2 - 5 } & $n_{e}$ & - & 0.31 & 0.33 \\
\cline { 2 - 5 } & $\alpha$ & $\mathrm{m}$ & 0.0029 & 0.0026 \\
\cline { 2 - 5 } & $M E$ & $\%$ & 99.2 & 99.9 \\
\hline
\end{tabular}

Explanation: $M E$ - model efficiency.

Table 4

Sorption parameters values calculated in the MATLAB environment and in the KLUTE-STEP programme

\begin{tabular}{|c|c|c|c|c|}
\hline \multicolumn{2}{|c|}{ Lithium ions } & MATLAB & KLUTE-STEP \\
\hline \multirow{2}{*}{ model } & parameter & unit & value & value \\
\hline \multirow{3}{*}{$\mathrm{H}$} & $K_{d}$ & $\mathrm{dm}^{3} \cdot \mathrm{kg}^{-1}$ & $1.82 \mathrm{E}-02$ & $2.56 \mathrm{E}-02$ \\
\cline { 2 - 5 } & $R$ & - & 1.10 & 1.14 \\
\cline { 2 - 5 } & $M E$ & $\%$ & 98.6 & 99.8 \\
\hline \multirow{3}{*}{$\mathrm{Ammonium} \mathrm{ions}$} \\
\hline \multirow{3}{*}{$\mathrm{H}-\mathrm{I}$} & $K_{d}$ & $\mathrm{dm}^{3} \cdot \mathrm{kg}^{-1}$ & $3.11 \mathrm{E}-01$ & $3.48 \mathrm{E}-01$ \\
\cline { 2 - 5 } & $k_{1}$ & $\mathrm{dm}^{3} \cdot \mathrm{kg}^{-1} \cdot \mathrm{s}^{-1}$ & $1.29 \mathrm{E}-05$ & $2.07 \mathrm{E}-06$ \\
\cline { 2 - 5 } & $R$ & - & 2.8 & 96.6 \\
\cline { 2 - 5 } & $M E$ & $\%$ & 97.9 & \\
\hline
\end{tabular}

Explanation: $M E-$ model efficiency.

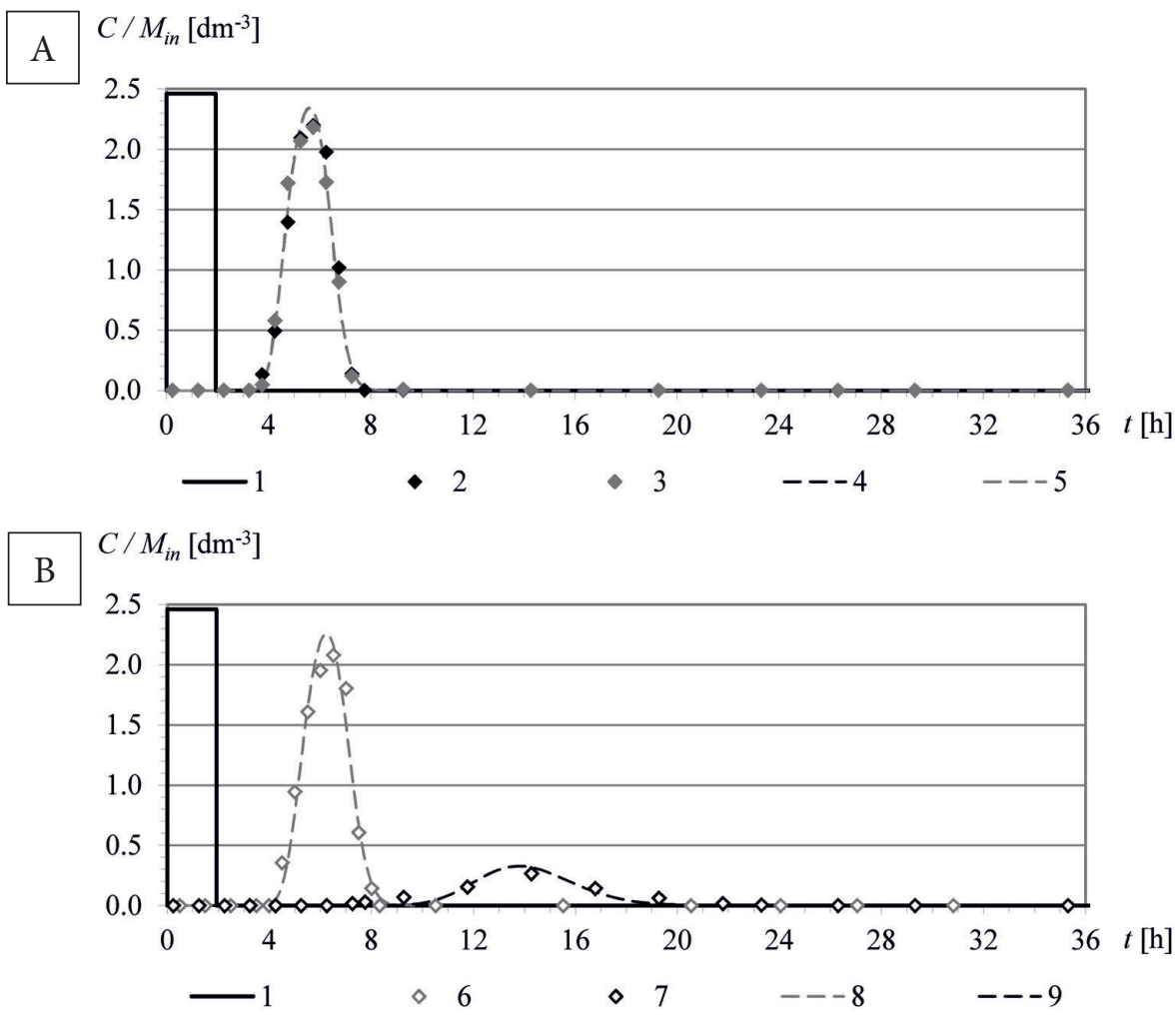

Fig. 6. Theoretical breakthrough curves of non-sorbed tracers (A) and reactive tracers (B) calculated, respectively, in the FIELD and KLUTE-STEP programmes, compared with experimental points: $C / M_{i n}$ - tracer concentration in relation to the injected tracer mass; 1 - injection, 2 - Cl experimental data , $3-\mathrm{NO}_{3}$ experimental data, $4-\mathrm{Cl}$ A-D model, $5-\mathrm{NO}_{3} \mathrm{~A}-\mathrm{D}$ model, $6-\mathrm{Li}$ experimental data, $7-\mathrm{NH}_{4}$ experimental data, 8 - $\mathrm{Li} \mathrm{H}$ model, $9-\mathrm{NH}_{4} \mathrm{H}-\mathrm{I}$ model 

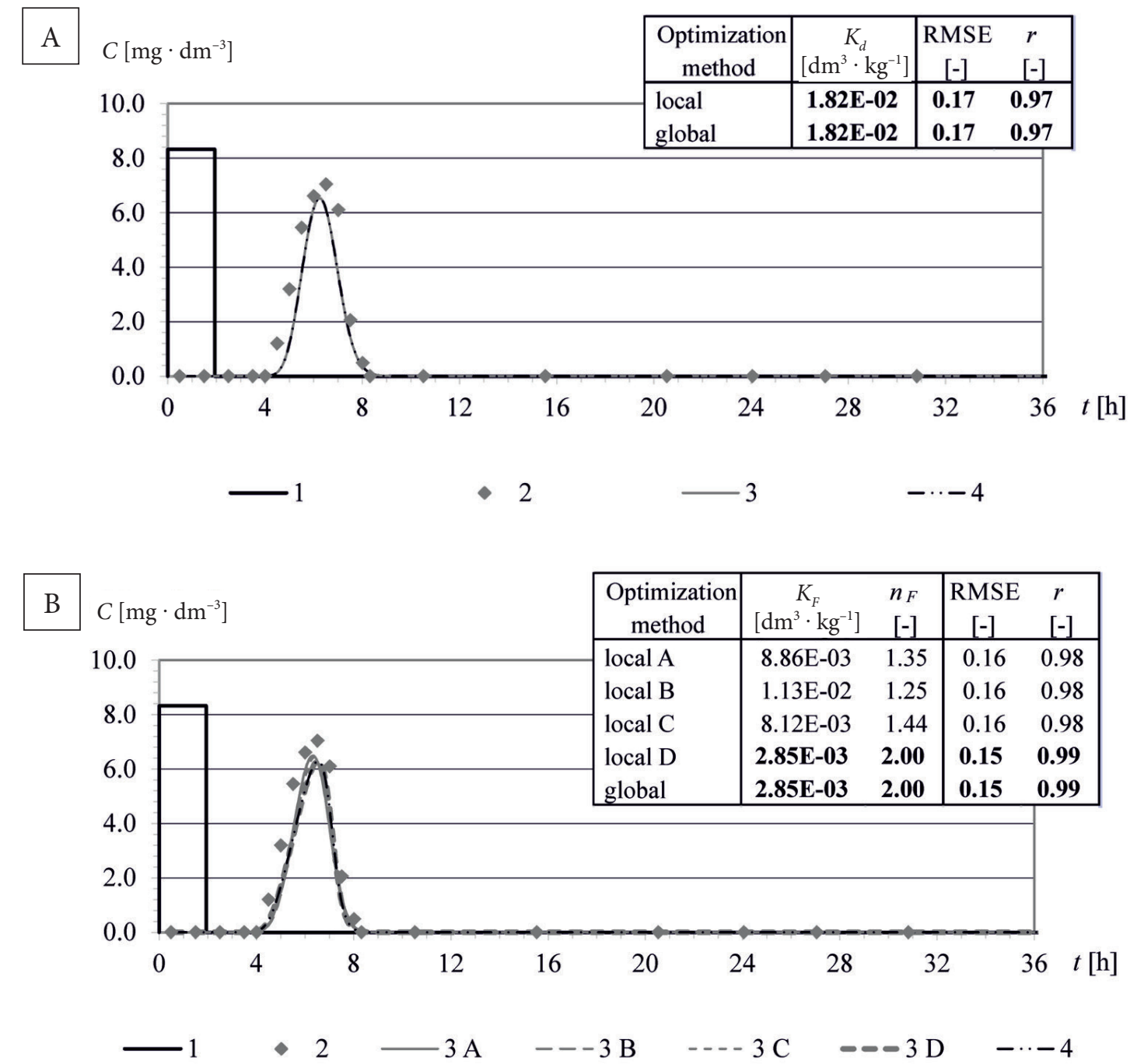

Fig. 7. Solutions using local and global optimization, lithium ions, $H$ model (A) and F model (B): 1 - injection, 2 - experimental data, 3 - local, $3 A$ - local A, 3B - local B, 3C-local C, 3D - local D, 4 - global; the table shows the identified sorption parameters values and the calculated RMSE and $r$ indicators of fitting the theoretical breakthrough curves to experimental points

In the case of ammonium ions, the best fitting for F-I model was achieved with the numerical optimization method. It is confirmed by fitting indicators calculated at measurement points. However, the symmetrical distribution of experimental points implies that the nature of ammonium ions migration in the analysed case is better reflected by H-I model (Fig. 8). In the literature, there are methods of analysing ammonium ions migration that combine non-equilibrium processes with both the Freundlich model and the Henry model (Moazed 2008, Jellali et al. 2010).

Retardation $R$ estimated by comparing the lithium ion breakthrough curve with the chloride ion breakthrough curve was 1.15 , whereas in the case of ammonium ions it was 2.7.
When analysing the results of parameter estimation, it should be noted that the described models assume the lack of ion competition during the process of sorption and the absence of other active ions in the solution. The accuracy of these assumptions has not been verified and should be examined in future studies.

The algorithms of the global and the local optimization methods complement each other. Global optimization focuses on finding the solution for the complete range of input values, whereas local optimization provides more detailed solutions.

Furthermore, the proper selection of the most adequate model can be evaluated using additional indicators, e.g. ones characterizing the shape of the recorded breakthrough curve. 

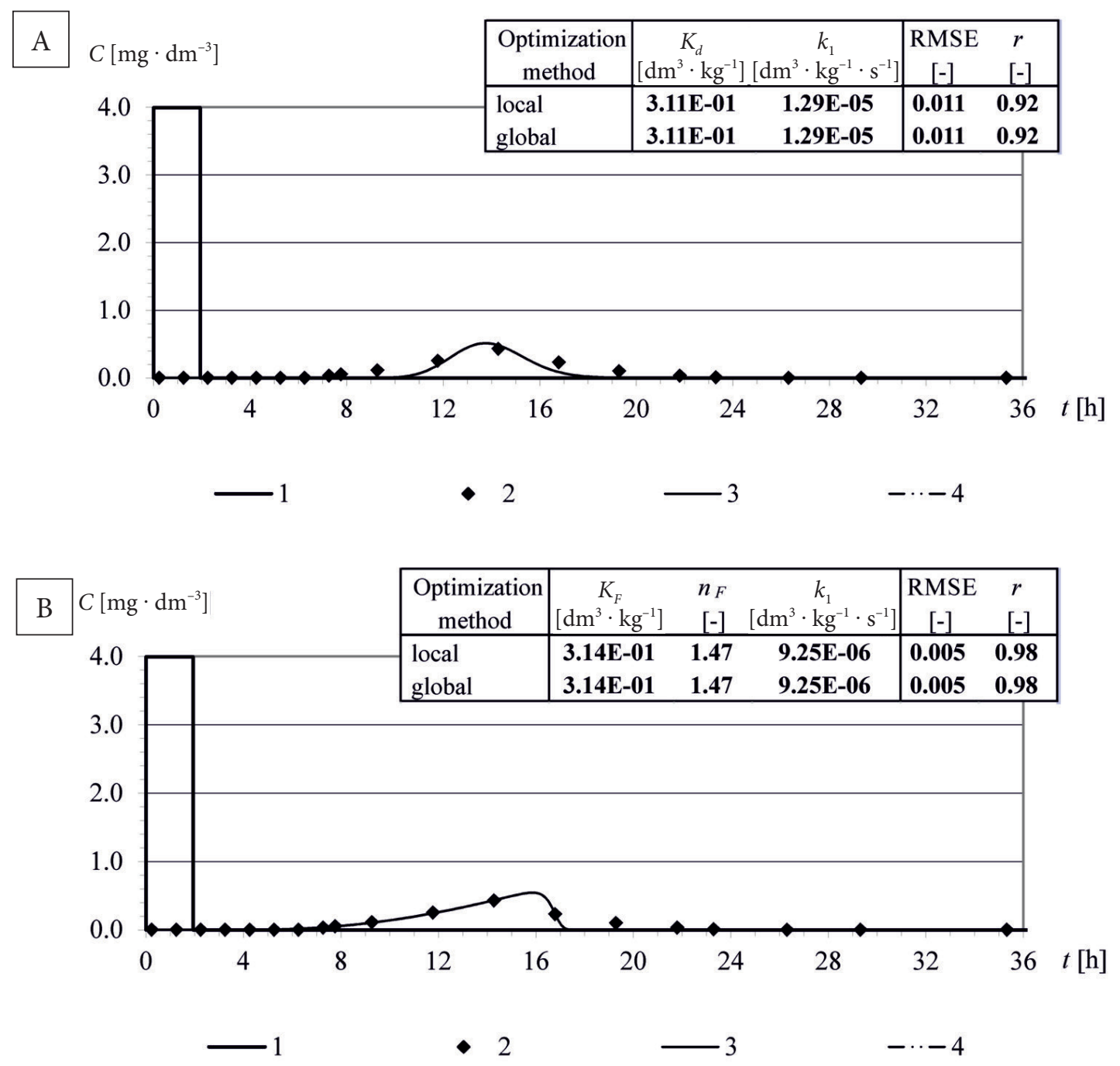

Fig. 8. Solutions using global and local optimization method, ammonium ions, H-I model (A) and F-I model (B): 1 - injection, 2 - experimental data, 3 - local, 4 - global; the table shows the identified sorption parameters values and the calculated RMSE and $r$ indicators of fitting the theoretical breakthrough curves to experimental points

\section{CONCLUSIONS}

As a result of the research, the authors identified migration parameter values for chloride, nitrate, lithium and ammonium ions transported through a sample of medium sand from near the Tursko groundwater intake. The established hydraulic conductivity is $k=4.17 \mathrm{E}-4 \mathrm{~m} \cdot \mathrm{s}^{-1}$, effective porosity $n_{e}=0.31$, and longitudinal dispersivity $\alpha$ is $0.003 \mathrm{~m}$. The nature of lithium ion migration is best described by a simple sorption model (equilibrium sorption), and that of ammonium ion by the hybrid model with irreversible sorption. On the basis of the value of retardation $R$, it was found that during migration through the soil sample lithium ions show low sorption intensity (Osmęda-Ernst \& Witczak
1991), while ammonium ions show medium intensity. Nitrate ions were transported at the same rate as chloride ions, exhibiting no retardation.

The verification of the calculation results carried out using the alternative analytical-numerical methods proved that the parameter estimation procedure applied by the authors in the MATLAB environment identifies correctly the transport and sorption parameter values. At the same time, it showed that it would be advisable to supplement the indicators of the selection of the best fitting of the theoretical curve to the experimental curve with additional descriptors relating to the shape of the experimental curve.

In the article, the authors compared the values of the parameters obtained by means of global 
and local optimization methods. It was observed that both algorithms complement each other well. When making calculations with the global optimization method, the authors usually obtain one solution of the model, which is confirmed and/or detailed by the calculations performed with the local optimization method.

The results presented in this study were obtained as part of a research project financed from the $\mathrm{Na}$ tional Science Centre resources, allocated on the basis of decision number DEC-2011/01/B/ST10/02063.

\section{Symbol list}

$\alpha \quad$ longitudinal dispersivity [L],

$\alpha_{L} \quad$ Langmuir constant $\left[\mathrm{L}^{3} \cdot \mathrm{M}^{-1}\right]$,

$\beta_{L} \quad$ total sorption capacity of the solid phase $\left[\mathrm{M} \cdot \mathrm{M}^{-1}\right]$,

$\lambda$ decay constant $\left[\mathrm{T}^{-1}\right]$,

$\rho_{\mathrm{s}} \quad$ density of the porous medium $\left[\mathrm{M} \cdot \mathrm{L}^{-3}\right]$,

C tracer concentration in the liquid phase $\left[\mathrm{M} \cdot \mathrm{L}^{-3}\right]$,

$C_{i n} \quad$ tracer concentration in the injected solution $\left[\mathrm{M} \cdot \mathrm{L}^{-3}\right]$,

$C_{\text {out }}$ tracer concentration in the output solution $\left[\mathrm{M} \cdot \mathrm{L}^{-3}\right]$,

$C_{m} \quad$ measured tracer concentration $\left[\mathrm{M} \cdot \mathrm{L}^{-3}\right]$,

$C_{t} \quad$ calculated tracer concentration $\left[\mathrm{M} \cdot \mathrm{L}^{-3}\right]$,

$D$ hydrodynamic dispersion coefficient $\left[\mathrm{L}^{2} \cdot \mathrm{T}^{-1}\right]$,

$D_{M} \quad$ diffusion coefficient $\left[\mathrm{L}^{2} \cdot \mathrm{T}^{-1}\right]$,

$i \quad$ hydraulic gradient $\left[\mathrm{L} \cdot \mathrm{L}^{-1}\right]$,

$k \quad$ hydraulic conductivity $\left[\mathrm{L} \cdot \mathrm{T}^{-1}\right]$,

$k_{1} \quad$ irreversible sorption rate coefficient $\left[\mathrm{L}^{3} \cdot \mathrm{M}^{-1} \cdot \mathrm{T}^{-1}\right]$

$k_{2} \quad$ first reversible sorption rate coefficient $\left[\mathrm{L}^{3} \cdot \mathrm{M}^{-1} \cdot \mathrm{T}^{-1}\right]$,

$k_{3} \quad$ second reversible sorption rate coefficient $\left[\mathrm{T}^{-1}\right]$,

$K_{d} \quad$ Henry distribution coefficient $\left[\mathrm{L}^{3} \cdot \mathrm{M}^{-1}\right]$,

$K_{F} \quad$ Freundlich sorption coefficient $\left[\mathrm{L}^{3} \cdot \mathrm{M}^{-1}\right]$,

$L \quad$ column length [L],

$M \quad$ mass of tracer $[\mathrm{M}]$,

$M_{\text {in }} \quad$ injected mass of tracer [M],

$M_{\text {out }}$ recovered mass of tracer [M],

$M E \quad$ model efficiency [\%],

$n \quad$ total porosity [-],

$n_{e} \quad$ effective porosity [-],
$n_{F} \quad$ Freundlich sorption exponent [-],

$r \quad$ correlation coefficient [-],

$R \quad$ retardation [-],

RMSE root mean squared error [-],

$R R \quad$ mass recovery of tracer [\%],

$s \quad$ tracer concentration in the solid phase (total sorbed-phase concentration) $\left[\mathrm{M} \cdot \mathrm{M}^{-1}\right]$,

$s_{e} \quad$ tracer concentration in the solid phase throughout equilibrium sorption $\left[\mathrm{M} \cdot \mathrm{M}^{-1}\right]$,

$s_{n} \quad$ tracer concentration in the solid phase throughout non-equilibrium sorption $\left[\mathrm{M} \cdot \mathrm{M}^{-1}\right]$,

time $[\mathrm{T}]$,

$t_{\text {in }}$ time interval of the tracer injection, when $C(t)=C_{i n}$ at the input $[\mathrm{T}]$

$t_{m} \quad$ time of measurement [T],

$U \quad$ coefficient of graining non-uniformity [-],

Q volumetric flow rate $\left[\mathrm{L}^{3} \cdot \mathrm{T}^{-1}\right]$,

$x \quad$ distance $[\mathrm{L}]$.

\section{REFERENCES}

Boutilier L., Jamieson R., Gordon R. \& Lake C., 2008. Transport of Lithium Tracer and E. coli in Agricultural Wastewater Treatment Wetlands. Water Quality Research Journal of Canada, 43, 2/3, 110-117.

Cameron D.R. \& Klute A., 1977. Convective-dispersive solute transport with a combined equilibrium and kinetic adsorption model. Water Resources Research, 13, 183-188.

Coleman T.F. \& Li Y., 1994. On the convergence of reflective Newton methods for large-scale nonlinear minimization subject to bounds. Mathematical Programming, 67, $2,189-224$.

Deng H., Dai Z., Wolfsberg A.V., Ye M., Stauffer Ph.H., Lu Z. \& Kwicklis E., 2013. Upscaling retardation factor in hierarchical porous media with multimodal reactive mineral facies. Chemosphere, 91, 3, 248-257.

Dragon K., Kasztelan D., Gorski J. \& Najman J., 2016. Influence of subsurface drainage systems on nitrate pollution of water supply aquifer (Tursko well-field, Poland). Environmental Earth Sciences, 75, 100. DOI: 10.1007/s12665015-4910-9.

Fernandez-Garcia D., Illangasekare T.H. \& Rajaram H., 2004. Conservative and sorptive forced-gradient and uniform flow tracer tests in a three-dimensional laboratory test aquifer. Water Resources Research, 40, W10103. DOI:10.1029/2004WR003112.

Fetter C.W., 2001. Applied Hydrogeology. Prentice-Hall Inc., Upper Saddle River, New Jersey.

Fohrmann G., Małoszewski P. \& Seiler K.-P., 2001. Experimental determination of the copper \& antimony mobility in calcareous and none-calcareous aquifer sediments in columns and 1-D reactive transport modeling. [in:] Seiler K.-P. \& Wohnlich S. (eds.), New Approaches Characterizing Groundwater Flow, A.A. Balkema, Lisse, 315-319. 
Gomez-Hernandez J.J., Fu J. \& Fernandez-Garcia D., 2006. Upscaling retardation factors in 2-D porous media. [in:] Calibration and Reliability in Groundwater Modeling: From Uncertainty to Decision Making, IAHS Publication, 304, IAHS, 130-136.

Hendry M.J., Lawrence J.R. \& Maloszewski P., 1999. Effects of velocity on the transport of two bacteria through saturated sand. Ground Water, 37, 1, 103-112.

Jellali S., Diamantopoulos E., Kallali H., Bennaceur S., Anane M. \& Jedidi N., 2010. Dynamic sorption of ammonium by sandy soil in fixed bed columns: Evaluation of equilibrium and non-equilibrium transport processes. Journal of Environmental Management, 91, 897-905.

Katalog parametrów hydrogeologicznych, 2016, [on-line:] www. hydrometria.amu.edu.pl/badania-naukowe/badania-kolumnowe-migracji-zanieczyszczen/ [access: 20.01.2017].

Kleczkowski A.S., 1984. Ochrona wód podziemnych. Wyd. Geologiczne, Warszawa.

Leibundgut C., Maloszewski P. \& Külls C., 2009. Tracers in Hydrology. Wiley-Blackwell, Sussex.

Maloszewski P., 1981. Computerprogramm Field für die Berechnung der Dispersion und der effektiven Porosität in geschichteten porösen Medien. GSF-Bericht R 269, Gesellschaft für Strahlen- und Umweltforschung, München-Neuherberg.

Maloszewski P., 1997. Program Klute-Step (Version for step function). Neuherberg.

Małecki J.J, Nawalany M., Witczak S. \& Gruszczyński T., 2006. Wyznaczanie parametrów migracji zanieczyszczeń $w$ ośrodku porowatym dla potrzeb badań hydrogeologicznych i ochrony środowiska. Poradnik metodyczny. Uniwersytet Warszawski, Wydział Geologii, Warszawa.

Marciniak M,. Kaczmarek M., Okońska M. \& Kazimierska-Drobny K., 2009. Identyfikacja parametrów hydrogeologicznych $z$ zastosowaniem numerycznej symulacji krzywej przejścia oraz metod optymalizacji. Bogucki Wydawnictwo Naukowe, Poznań.

Moazed H., 2008. Ammonium ion removal from wastewater by a natural resin. Journal of Environmental Science and Technology, 1, 11-18.

Nocedal J. \& Wright S. J., 2006. Numerical Optimization. Springer Series in Operations Research, Springer Verlag.

Okońska M., 2006. Identyfikacja parametrów migracji zanieczyszczeń w porowatym ośrodku hydrogeologicznym metoda modelowania eksperymentu kolumnowego. Geologos
- Uniwersytet im. Adama Mickiewicza. Instytut Geologii, 9, Bogucki Wydawnictwo Naukowe, Poznań.

Okońska M., Kaczmarek M., Małoszewski P. \& Marciniak M., 2016. Identyfikacja parametrów filtracji i migracji z wykorzystaniem eksperymentu kolumnowego i optymalizacji w środowisku obliczeniowym MATLAB. [in:] Witczak S. \& Żurek A. (red.), Praktyczne metody modelowania przepływu wód podziemnych, Akademia Górniczo-Hutnicza im. Stanisława Staszica w Krakowie, Wydział Geologii, Geofizyki i Ochrony Środowiska Kraków, 175-185.

Osmęda-Ernst E. \& Witczak S., 1991. Niektóre problemy związane z laboratoryjnymi badaniami parametrów migracji metali ciężkich w wodach podziemnych. Zeszyty Naukowe Akademii Górniczo-Hutniczej w Krakowie. Sozologia i Sozotechnika, 1367, 31, 9-27.

Parker J.C. \& van Genuchten M.Th., 1984. Determining transport parameters from laboratory and field tracer experiments. Virginia Agricultural Experiment Station Bulletin, 84-3, Virginia Agricultural Experiment Station, Blacksburg.

Reimus P.W., Haga M.J., Adams A.I., Callahan T.J., Turin H.J. \& Counce D.A., 2003. Testing and parameterizing a conceptual solute transport model in saturated fractured tuff using sorbing and nonsorbing tracers in cross-hole tracer tests. Journal of Contaminant Hydrology, 62-63, 613-636.

Toride N., Leij F.J. \& van Genuchten M.Th., 1995. The CXTFIT code for estimating transport parameters from laboratory or field tracer experiments. Version 2.0. Research Report No.137,U.S.SalinityLaboratory, USDA, ARS, Riverside, CA.

Weber W.J. Jr., Mcginley P.M. \& Katz L.E., 1991. Sorption phenomena in subsurface systems: Concepts, models and effects on contaminant fate and transport. Water Research, 25, 499-528.

Witczak S., Kania J. \& Kmiecik E., 2013. Katalog wybranych fizycznych i chemicznych wskaźników zanieczyszczeń wód podziemnych i metod ich oznaczania. Biblioteka Monitoringu Środowiska, Główny Inspektorat Ochrony Środowiska, Warszawa.

Wrenn B.A., Suidan M.T., Strohmeier K.L., Eberhart B.L., Wilson G.J. \& Venosa A.D., 1997. Nutrient transport during bioremediation of contaminated beaches: evaluation with lithium as a conservative tracer. Water Research, 31, 3, 515-524.

Venkataraman P., 2009. Applied optimization with MATLAB programming. John Wiley \& Sons, Hoboken, New Jersey. 